\title{
A Preliminary Study of the Reason for the Change of Pang Xun-Qin's Ideology of Layout Education
}

\author{
$\mathrm{Li} \mathrm{Li*}$ \\ Nanjing Museum, No.321 East Zhongshan Road, Nanjing, China \\ *Corresponding author. Email: 58532515@qq.com
}

\begin{abstract}
Pang Xun-Qin is well known as the founder of the modern art layout education in China. It is rarely known that he was also shortly engaged in the ethnic art investigation in the national central museum during the period of republic of China, which has a significant impact on the generation of his educational ideology about the art layout education. In this paper, we systematically reorganize the art ideology of Pang Xun-Qin and his study experience in Paris based on the literature method and the oral account of the little daughter of Pang Xun-Qin. We further unravel the relation between the Chinese ethnic art and the turning points of the embryo of Pang Xun-Qin's art ideology. Hence, we reveal the reason why Pang Xun-Qin, an artist and ideologist of the layout education, was devoted to the archaeology and ethnic investigation in the national central museum, which has superficially nothing to do with the art in order to understand the reason for the change of Pang Xun-Qin's ideology of layout education. which has superficially nothing to do with the art. Keywords: Pang Xun-Qin, national central museum, art layout, layout education
\end{abstract}

\section{INTRODUCTION}

Pang Xun-Qin is one of the most influential artists of the 20th century in China, whose biggest contribution is building the education system of China's art and craft and modern layout as a founding father of Central Academy of Art and Craft (predecessor of School of Fine Art, Tsinghua University) and the founder of modern layout and art layout education in China. Yet it is unknown to many that his experience in National Central Museum and his involvement in the ethnic art investigation in Southeast China during this period constituted a significant turning point in his thinking on China's modern art, with farreaching influence on Pang's career as an artist and even the art layout education system in China. The initial purpose of this paper is attempting at answering a question that has long puzzled the research group,i.e. why would he engage in archeological research and ethnic investigation in National Central Museum as it seems irrelevant to art? Yet most of the current research on Pang Xun-Qin is limited within art itself, with many publications on his artistic achievements while most of Pang's research in history and culture, ethnology and anthropology remain little known, especially his experience in National Central Museum which almost goes unnoticed. Currently, there is no book specializing on Pang Xun-Qin's research experience during this period and there are only approximately a dozen papers published, most of which are solely from an art perspective or limited within ethnology and history, with Discussion on the Values and Inspiration of Pang Xun-Qin's Investigation on Ethnic Minorities' Artas the only exception based on cross-disciplinary research. [1] Therefore, elaboration of this point represents a major step in analyzing how Pang's art ideology took shape and fill the gap in the history of art education.

\section{WHAT IS PANG XUN-QIN'S ART IDEOLOGY?}

An analysis of Pang Xun-Qin's art ideology should be conducted before answering the question on why Pang came to National Central Museum. Pang Xun-Qin's art ideology boils down to exploring into the path of modern Chinese art and layout, for which he waged strenuous efforts throughout his life. According to Pang himself, "My life is a road where I explore, explore and explore."

Based on available literature [2] and our research on the key turning points of Pang Xun-Qin's thinking on art, his art ideology evolved through the following three stages:

First, the infancy stage: during which he studied art in Europe and completed his learning and contemplations on modern western art.

Second, the maturity stage: when he returned to China for deeper exploration into oriental art. During the antiJapanese war, he was in National Central Museum where he engaged in an investigation into ethnic minorities in southwest China, contemplating on the relationships between ethnic and folk-art study and modern art layout. Third, the implementation stage: during which he put what he studied into practice and founded Central Academy of Art and Craft.

Details of each stage (except for the second stage) have been elaborated in many writings on modern art history and will not be repeated here. 


\section{SEVERAL CRITICAL CHANGES IN PANG XUN-QIN'S ART IDEOLOGY IN THE FIRST STAGE}

An analysis of the above stages shows that Pang Xun-Qin's work in National Central Museum took place in the second stage, i.e. maturity stage. In order to find his motivation in engaging in the work in National Central Museum, we need a close examination of his experience in the first stage of the evolution of Pang Xun-Qin's art ideology, i.e. the infancy stage, investigating what he experienced during this period and how these experiences influenced his art ideology. A few major events occurred to Pang in this stage.

\subsection{From Medicine to Art}

According to Pang Xun-Qin's youngest daughter Prof. Pang Qi, two incidents occurred during this period.

\subsubsection{The first event}

Prof. Pang Qi started to doubt the integrity and rigorousness of practitioners of natural sciences due to attempted dishonesty in a medical examination.

Prof. Pang Qi recalled that Pang Xun-Qin studied in a missionary school in Shanghai before going to France at the age of 19. Priests were kind to the students and Pang was especially favored by one of the priests. During a medical examination of which all questions were in Latin language and students were asked to mark an orthopedic anatomy with corresponding words. Pang was still racking his brains in front of many blank answers while many of his classmates had already finished and submitted the papers, when the priest came to him and told him the answer. After receiving the marked papers, Pang wrestled with his mind and was eventually convinced that it was very inappropriate. First, medicine should tolerate no cheating or dishonesty; second, such behavior was wrong for a priest, and he was stung by a guilty conscience. This incident had a major impact on Pang Xun-Qin and changed his mind of studying medicine.

\subsubsection{The second event}

A Russian priest asserted that no artist would be born in China, which aroused Pang Xun-Qin's self-esteem for his nationality and strengthened his conviction of pursuing an art career.

According to Prof. Pang Qi, her father became enthusiastic in painting since childhood, and the family hired a private tutor for him, yet the tutor was so amazed by the young boy's painting skills that he would not be qualified to teach him. After giving up on medical studies, Pang Xun-Qin acquainted himself with another Russian priest who took a liking on him. As they were chatting one day, Pang confessed about his enthusiasm in painting throughout the years and his dream of becoming an artist, only to be snapped at by the priest whose pleasant countenance changed, "let me tell you the truth, no Chinese can ever become a great artist!" In the eyes of most foreigners, art was for the elites while Chinese was an inferior people that should never venture into art. Before the founding of China, the Chinese people were belittled as inferior, even in the eyes of priests of a missionary school who always presented a pleasant and kind countenance. For Pang XunQin, such words coming out of the mouth of a priest were completely unacceptable and insulting, to which he responded, "Reverend, you just wait and see!" [3] He returned to his dormitory, packed up and quitted school, making up his mind to study art in Europe and prove that Chinese can become great artists as well.

\subsection{From Dedication to Painting to Growing Enthusiasm in Art Layout}

Pang Xun-Qin went to pursue his studies in France at the age of 19, setting foot on a life career of art. Born in a well-off family, he received his primary education in a missionary school in Shanghai and spoke fluent French, which helped him to fit into the French society. Confident in his life and education background in Shanghai which was "much of an eye opener" as he was, Pang was amazed and attracted by the myriad of art forms in Paris, which expanded from ancient painting, modern painting, architecture up to poetry, music and dance. Modern western painting represented by fauvism advocated by Henri Matisse prospered during that period, and, like many Chinese artists studying abroad, Pang Xun-Qin felt the strong influence of contemporary western art in his studies, and joined his peers in discussions on how to learn from contemporary western art and prepare for an "art revolution" in China and explore the Chinese way of contemporary painting. Therefore, Pang Xun-Qin was dedicated to pure painting in the beginning of his study until he visited 1925 Art Deco Exhibition in Paris, which, judged from the subsequent historical evolution, unveiled a major transition in the modern history of layout as it marked the birth of Art Deco Movement. That is to say, France was in the thriving period of contemporary art as well as modern history of layout when Pang went to pursue his studies. It was this exhibition that introduced Pang into another important yet generally overlooked, or unknown discipline of western art-modern art layout existing alongside with painting. (The essential differences between painting and layout and the important stages of modern art layout will not be elaborated in this paper. See A History of Modern Design, Wang Shou-Zhi [4].) For Pang XunQin, this exhibition shed light on the importance of contemporary layout and was no less than an enlightenment enabling his transition from pure painting to China's contemporary art layout and education, although he was hardly aware what modern layout really meant at that time. 
"My father was deeply touched by the Exhibition at the Grand Palace during his study in Paris, of which the influence on him was unprecedented. The Exhibition was all about people's daily life-clothing, food, habitation and transport, reminding him that beauty is not only about paintings; instead, it is part of life. Beauty is ubiquitous." said Prof. Pang Qi. Since then, Pang Xun-Qin became fervent in art deco. However, by that time the Industrial Revolution was completed in the western hemisphere, with Tour Eiffel proudly poised in Paris; while China still relied on imports for basic needs such as cloth and candles, where needy people were suffering in poverty and tribulations, and the good taste of fashion was too much of a luxury when people struggled to put bread on the table and garments on their backs. "Why should people be deprived from beauty as part of everyday life-clothing, food, habitation and transport?" the question flashed across Pang Xun-Qin's mind. Coming from the most developed city in China, he was shocked by the huge gap between the two hemispheres, and it was not until then that he became aware of Cai Yuan-Pei's concept of "saving the nation by art education" and the importance of art education itself. He believed that China should have its own Bauhaus. This was how he first came up with the idea of establishing the Central Academy of Art and Craft. He visited Bauhaus in Germany before returning to China, and was immensely touched by such a design institute and was all the more determined to pursue a career in layout back to China.

Prof. Pang Qi believes that the greatest contribution as well as the worst tribulation of her father came from his career in layout. During his studies abroad, Pang Xun-Qin made some early attempts in the practice of layout. When working on the layout part of Pang Xun-Qin's art chronicles, Prof. Pang Qi found that much of the history of modern craft design in China was related with her father.

\subsection{From Interest in Western Modern Art to Awakened Awareness of the Value of Oriental Art}

The transformation of Pang Xun-Qin's art career was influenced by two key figures:

\subsubsection{The first one was CHANG YU}

Under influence of Chang Yu, Pang Xun-Qin became aware of the artistic value of oriental culture and tried applying the techniques of oriental painting in western painting, using painting brush for line drawing.

Pang Xun-Qin went abroad at the age of 19 and studied for 5 years in France, during which time most artists studying overseas were in Ecole des Beaux-Arts in Paris. Yet Pang was enrolled in Académie Julian upon recommendation by Jiang $\mathrm{Bi}-$ Wei, and got acquainted with Chang $\mathrm{Yu}$ while he was clouded with doubts in his pursuit of western painting. Chang $\mathrm{Yu}$, an insightful artist with strong personality, advised Pang to sharpen his painting techniques in
Académie de la Grande Chaumière rather than a normal academy of art where art education is conventionalized and lifeless. Académie de la Grande Chaumièrewas an art school newly established by a Swiss female artist in France at the time, which, in sharp contrast with the rules and frameworks of academism, provided a liberal and unconventional atmosphere of learning and was the cradle for many famous artists, eventually making the local community a Bethlehem for artists. A well-known café in a nearby street became a haven for artists and Picasso himself was on the list of frequent customers. It was in such an atmosphere that Pang Xun-Qin received his western art education, learning about western art while awakening to the value of oriental art. During this period, Pang started to try line sketching with a painting brush, endowing western painting the spiritual rhythm of artistic lines and curves from the Orient. However, Pang XunQin's understanding of oriental art apparently remained on a superficial level-skills and techniques.

\subsubsection{The second one was a renowned French art critic}

The other influential personage was a renowned French art critic, whose words prompted Pang Xun-Qin to return to China for in-depth research on traditional Chinese art. During his attempts into western painting merged with oriental techniques in Académie de la Grande Chaumière, he rose to fame in Paris and was eager to host a solo exhibition. At that time, inviting an influential art critic for comments was indispensable to a successful solo as it would help with the esteem and reputation of the exhibition. Introduced by a friend, Pang Xun-Qin brought his works to the most prominent art critic in Paris, who said, "Young man, I know what your works look like without having to open them. What do you think you can paint at your age? You come from a country with the treasure of time-cherished history and culture, but have you got any deep understanding of your local traditional art? Have you ever explored into that?" Pang was dumbfounded; as a young man in his twenties, his knowledge about traditional Chinese art was limited, and he responded with honesty, "No, sir, my knowledge is too limited." "Then I can imagine what your paintings look like. My advice is that you should go back to your country, understand it, go deeper before creating your art. If I get to live to see your achievements in all this, I promise I'll write comments for you." The conversation was lifechanging for Pang Xun-Qin's career as an artist. As Prof Pang Qi recalled, it was a critical moment of her father's life that showed him the right way, so he returned to China in his twenties and founded the Storm Society (Juelan She) upon arrival at his hometown, Changshu. Wearing a traditional long garment, painting brush in hand as he practiced line drawing, he felt a world of differences although he used a painting brush in France as well. Through strenuous and tireless efforts in line drawing, he 
learned that the line in Chinese line drawing was more than a line itself, but with rich implications.

The establishment of the Storm Society in October 1932 opened a new page in China's modern art movement as the cradle of conceptual art, marking that art in China was ushered into a new historical stage. Pang Xun-Qin and Ni Yi-De were the first to motion the creation, and in Manifesto of the Storm Society authored by Ni Yi-De appeared the statement, "Let us Rise! With passion like storm and reason like iron, let us create a world interlaced with colors, lines and shapes!" [5] According to Huang Jian-Wu, deputy research fellow of Chongqing Research Institute of Culture and Art, "(the Storm Society) vocally expressed an anti-conventionalist (obsolete practices in traditional Chinese painting and conventions of western realism) stand of art as well as a clear-cut intention to learn from modern western painting and to innovate." "The Storm Society was indeed an Enlightenment Movement in modern painting despite its imperfections." [6]

\section{THE INFLUENCE OF HIS STUDY IN PARIS ON THE EARLY STAGE OF PANG XUN-QIN'S ART IDEOLOGY}

The influence of his study in Paris on the early stage of Pang Xun-Qin's art ideology can be summarized in the following aspects:

\subsection{Introduction to Another Discipline of Art- Modern Layout, Emergence of Interest in Modern Layout (Especially Deco Layout)}

The Industrial Revolution in the western hemisphere transformed people's life while the deco layoutmade daily utensils glow with beauty, which, for Pang Xun-Qin, could be channels to revive the Chinese nation struggling in distress and tribulations at that time. Such an interest was closely linked to his personality. As an artist, Pang XunQin was not only a romantic idealist but also a keen enthusiast in the society and the life of the common people. According to Prof. Pang Qi, "My Father was an altruist who was loving and caring. The most commonly used word for him was 'people' and he put people as his priority all his life. His generation was a generation of patriotists who could have enjoyed a more comfortable life overseas but didn't. And the Storm Society was created by a group of young returnees, whose manifesto remains inspiring today. Having seen the development in the West during their studies overseas, they wanted to bring back the development to China, aspiring for a stronger China in their words, their deeds and their undertakings." Such patriotic ambitions in mind as a young man in his twenties inspired Pang Xun-Qin later to engage in the investigation in ethnic minorities in Southwest China initiated by National Central Museum.

\subsection{Birth of Modern Layout Art Education}

Closely relevant to the last paragraph, Pang Xun-Qin's goal for modern layout of China was not limited to his own exploration of layout as an art, but rather approaching from the popularization of art education, addressing layout education from the perspective of education itself. Traditionally in China, crafts and techniques were imparted from master to apprentice without the concept of education, and learning a craft was merely prompted by the need of making a living rather than motivated by appreciation for beauty, let alone developing art education.

\subsection{Re-awakening and Consciousness of the Value of Chinese Art and Recognition of the Importance of In-depth Research on Traditional Chinese Art and Art Deco Inspired by the Study Experience of Western Art, Showing Pang Xun-qin the Direction for Art Research Later in National Central Museum}

Pang Xun-Qin's decision to engage in National Central Museum resulted from the influence of several key art ideologies during his study in Paris. Yet it should be noted that Pang was still unclear about the concepts such as "what is modern layout in China" and "how to implement modern Chinese layout and its education" during this period. In Prof. Pang Qi's words, it was a period of "stagewise rather than holistic clarity". These concepts evolved with increasing clarity during his research in National Central Museum and were implemented during his engagement in the Museum, gradually evolving, sublimating until maturing in practice.

In summary, we came to an understanding how Pang XunQin became the founder of layout education in China and the reasons for the ideological shift in his layout education.

\section{CONCLUSION}

To summarize, Pang Xun-Qin is the cofounder of the Central Academy of Art and Craft and the modern arts and crafts in China. He has made an indelible contribution to the modern layout and art layout education in China. It is his working experience in National Central Museum that changes him from an ordinary painter to the begetter of modern arts and crafts, and devotes him to the career of founding the art and layout education. From this paper, we find the reason that Pang Xun-Qin changed his educational ideology on layout lies in the influence of his oversea study experience in Paris on his early art ideology, which also makes him aware of the importance of layout and Chinese traditional folk art for building the layout education in China. 


\section{REFERENCES}

[1] Y. Zeng, Discussion on the values and inspiration of Pang Xun-Qin's investigation on ethnic minorities' art, Guizhou Ethnic Studies, 04(2015).

[2] M. Zhou, 'Studies on the Art and Art Education of Pang Xun-Qin', Tsinghua Express, Beijing, 2010, pp1719.

[3] X. Q. Pang, That is My Way, SDX Joint Publishing Company, Beijing, 2005, pp 59.

[4] S. Z. Wang, History of Graphic Design, China Youth Publishing Group, Beijing, 2002.

[5] Y.D. Ni, Journal of Art, 5(1932).

[6] J.W. Huang, 'Juelan Society, a regretful enlightenment of modern painting', World of Public Relations, 10(2018). 